\title{
As Meias Esportivas
}

Figueiredo M. ${ }^{1}$

${ }^{1}$ Uberlândia - Brasil.

E-mail:drmarcondes@gmail.com

Figueiredo, M. 2013. As Meias Esportivas, p.66. In: Bastos, Francisco Reis. Anais do V Simpósio Internacional de Flebologia [Blucher Medical Proceedings n.1 v.1]. São Paulo: Blucher, 2014 http://dx.doi.org/10.5151/medpro-flebo-SIF_40
O uso da meia elástica está bem estabelecido na prática clínica, no contexto da medicina baseada em evidências, tanto para profilaxia quanto para o tratamento de patologias linfáticas e venosas ${ }^{1}$. Além disso, o efeito benéfico das meias elásticas já atingiu a prática esportiva, proporcionando mais conforto aos praticantes de algumas modalidades ${ }^{2,3}$. No contexto esportivo, o principal objetivo do uso da meia é melhorar o desempenho do atleta e proporcionar boa recuperação após o esforço físico.

Em relação ao uso da meia elástica na prática esportiva, a literatura sugere um benefício indireto, com menores níveis de ácido lático pós-atividade, redução de trauma muscular e melhora no desempenho e no retorno venoso ${ }^{4}$. Foram avaliadas dez jogadoras profissionais de voleibol, com idades entre 18 e 25 anos, utilizando ou não meia elástica (Sport Active $^{\circledast}$, Venosan, Abreu e Lima, Brasil), com compressão de 20 a $30 \mathrm{mmHg}$ abaixo do joelho. As dosagens foram feitas em três momentos: M0, início da manhã, com as atletas em repouso sem uso de meia elástica; M1, início da manhã, após a realização de atividade física com uso de meia elástica; M2, sete dias depois, após a realização dos mesmos exercícios, porém sem uso de meia elástica. Aplicou-se a escala de Borg após cada série de atividade física para avaliação do esforço. Concluimos que o uso da meia elástica foi associado a menores níveis plasmáticos dos biomarcadores de lesão muscular após exercício físico.

Palavras chaves: meias de compressão; desempenho atlético; atividade física.

\section{Referências}

1. Partsch H, Flour M, Smith PC. Indications for compression therapy in venous and lymphatic disease consensus based on experimental data and scientific evidence. Under the auspices of the IUP. Int Angiol. 2008;27:193-219.

2. Simao R, Farinatti Pde T, Polito MD, Maior AS, Fleck SJ. Influence of exercise order on the number of repetitions performed and perceived exertion during resistance exercises. J Strength Cond Res. 2005;19:152-6.

3. Ali A, Caine MP, Snow BG. Graduated compression stockings: physiological and perceptual responses during and after exercise. J Sports Sci. 2007;25:413-9.

4. Berry MJ, McMurray RG. Effects of graduated compression stockings on blood lactate following an exhaustive bout of exercise. Am J Phys Med. 1987;66:121-32. 